\title{
The Effects of Driving Environment on the Mental Workload of Train Drivers
}

\author{
Nurul Izzah Abd Rahman ${ }^{\dagger 1}$, Siti Zawiah Md Dawal ${ }^{2}$ \\ and Ardeshir Bahreininejad ${ }^{3}$ \\ Department of Mechanical Engineering, Faculty of Engineering, \\ University of Malaya \\ 50603 Kuala Lumpur, Malaysia. \\ Tel.: +603-79675384, Fax: +603-79675317 \\ Email: ${ }^{1}$ izzahrahman@um.edu.my \\ 2sitizawiahmd@um.edu.my \\ 3bahreininejad@um.edu.my
}

Keywords: Mental workload, EEG, train driving, simulation experiments

\begin{abstract}
A study is carried out to investigate the effects of driving environment on the mental workload of train drivers while driving. The driving task is performed under three environmental conditions, i.e. clear sunny day, rainy day and rainy night driving. Electroencephalography (EEG) measurements are recorded from the Fz and $\mathrm{Pz}$ channels of fifteen male subjects aged between 24 to 48 years old. The mean alpha power is monitored as a function of time as this signal reflects the variations in mental workload of the drivers. The results exhibit that the signal pattern for rainy night driving condition is significantly different compared to others. This finding indicates that the train drivers show an increase in mental workload after six minutes of driving under rainy night condition. The results demonstrate a percentage difference in mean alpha power of $37 \%$ between daytime and rainy night driving conditions during the early periods of driving. This indicates that the mental workload of train drivers tends to be low with an increased level of sleepiness under such conditions, which are signs of low vigilance.
\end{abstract}

\subsection{Introduction}

Having an appropriate level of mental workload is important for human operators due to the fact that each individual is expected to perform specific tasks according to expectations. According to Hwang et al. [1], the performance indicator for most human operators will degrade if the mental workload is either too high or too low. Human operators may suffer from delays in information processing and they may be unable to respond to the incoming information when the capacity to process information exceeds the maximum limit [2]. It is also stated that human operators will become bored with an increased tendency to make mistakes when their mental workload is significantly lower than the appropriate level. Almost $75 \%$ of all train accidents can be associated to human error [3]. For example, in India, BBC News India reported on $22^{\text {nd }}$ May 2012 that 24 people were killed and 25 were injured after a passenger train collided with a stationary goods train which was said to be caused by carelessness of the train driver who overshot a communication signal.

The primary principles of train driving are essential for safety and performance [4]. One of these principles is that the drivers must be able to maintain sufficient attention in order to monitor the incoming information as well as changes in the predicted environment. The train drivers are expected not to suffer from boredom and they must remain fully alert at all times. Furthermore, the train drivers are expected to be able to see and reach all equipment related to monitoring, controlling and receiving feedback. The control panel of the train is involved in such situations and therefore its design should ease train drivers in fulfilling the required task [4].

A driver's workload can be described as the relationship between the driver and the driving task. Parkes [5] stated that the primary task of a driver is the safe control of the vehicle within the traffic environment. Ergonomists are concerned with the drivers' mental workload since information overload may lead to distractions while driving [6, 7]. According to De Waard [8], 
there are a number of factors that influence the driver's workload, in which several are environmental factors.

A number of studies were devoted on investigating the influence of mental workload after realizing the significance of this human factor. Physiological measurements are known to be effective methods to evaluate mental workload $[1,2,9,10]$ and Electroencephalography (EEG) is shown to be an accurate method for quantitative measurements of human performance $[2,10,11]$. Based on a comprehensive review on related works in this area, it is found that most studies primarily used EEG to monitor the driving performance of road drivers $[12,13]$ and there are a limited number of studies which used EEG to measure the mental workload of train drivers. Owing to the importance of investigating the mental workload of train drivers, this study is aimed to investigate the effects of driving environment on the mental workload of train drivers while driving, in which EEG is implemented for this purpose.

\section{Methodology}

\subsection{Subjects}

Fifteen train drivers (male) were recruited to participate in the experiment, aged between 24 to 48 years old ( $40 \pm 6.9$ years) and working experience of $14 \pm 6.1$ years. Each participant has a valid train driving licence and is free from serious illnesses and medications which would otherwise limit the compliance of subject requirements and influence the physiological measurements.

\subsection{Apparatus and Materials}

The brain activity of each participant was recorded using EEG BIOPAC MP150 System equipped with AcqKnowledge 4.0 software as well as Electrode Cap (CAP100C). The electrooculogram (EOG) was used to detect the presence of eye blinks in the EEG data.

\subsection{Experimental Procedure}

The experiments were carried out in a room which consists of a computer-based train driving simulator (Mitsubishi Electric Advance, Japan) provided by Keretapi Tanah Melayu Berhad (KTMB). The participants' demographic data are collected prior to initiating the driving task. Three sessions were conducted to simulate three driving conditions, one session for clear sunny day, rainy day and rainy night, respectively. The participants were requested to complete 60 minutes of monotonous train driving session, in which each session has a total duration of 20 minutes. The measurement procedure was repeated for each session, and the participants were given a 5-minutes break after each session. The participants were required to complete all three driving sessions and they were given a few minutes to familiarize themselves with the controls and the experimental setup in order to perform the train driving task.

\subsection{Electroencephalography (EEG) Data Collection and Analysis}

The EEG (Figure 1) records the brain signals during the monotonous driving sessions. The EEG signals were acquired from the $\mathrm{F}_{Z}$ (intentional and motivational centres) and $\mathrm{P}_{Z}$ (perception and differentiation) electrodes, based on the international 10-20 electrode placement system [13] with an electronically linked earlobe reference as in Figure 2. The EOG measurements were carried out by placing the electrodes above and below the eyes on the right side of the head. 


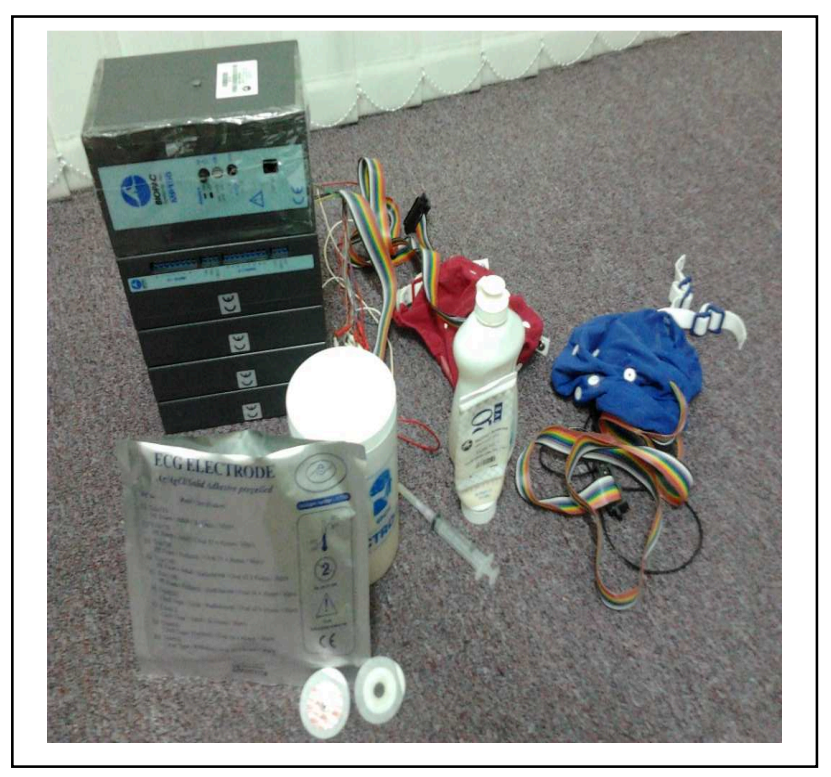

Figure 1: Equipment used for EEG recording

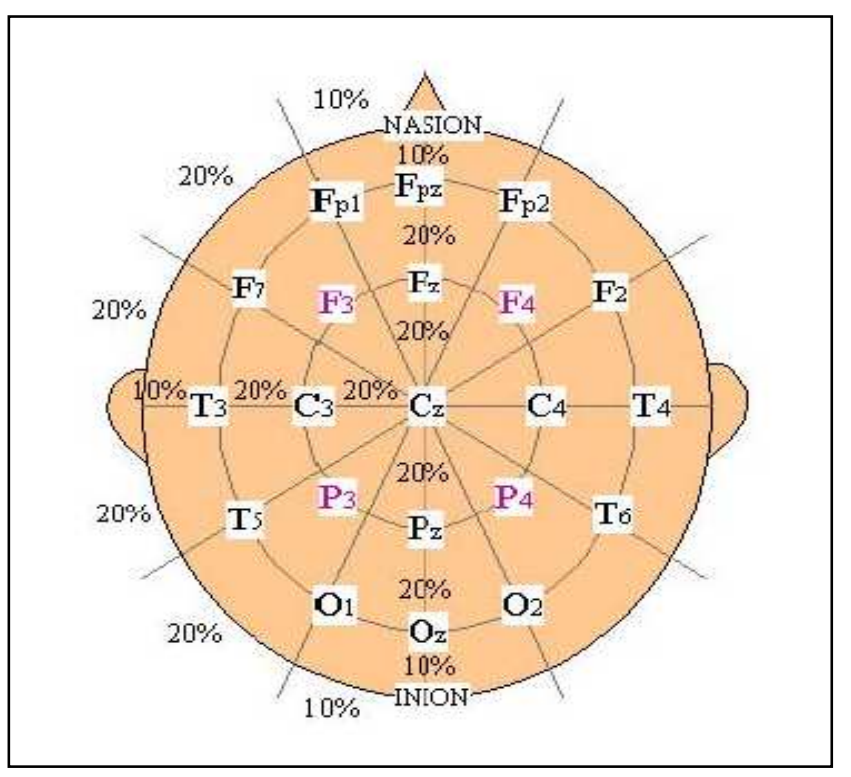

Figure 2: Labels for points according to the international 10-20 placement system [14].

The EEG alpha band is defined as the frequency between $8-13 \mathrm{~Hz}$. The first 120 -seconds intervals of the physiological signals from the beginning of each period were excluded from the analysis in order to eliminate drifts. The mean alpha power values were computed over a period of 3 minutes, corresponding to one time interval. It is known that EEG data are susceptible to noise (i.e. eye movement artefacts in this case) at numerous points during the recording process [9] and the EOG data were used to remove these artefacts as a measure of the blink interval. Fast Fourier Transform (FFT) analysis was performed to extract and estimate the mean alpha power at each time interval and the data were smoothed using a 100\% Hanning window. The Friedman Test was used to analyze the significant difference between the mean alpha power data for the three train driving sessions (S1, S2 and S3) over a total period of 18 minutes, corresponding to 6 time intervals.

\subsection{Results}

\subsection{EEG Mean Alpha Power for Train Driving Task}

It is found in this study that the driving conditions have a significant impact on the EEG's mean alpha power range $(8-12 \mathrm{~Hz})$. The mean alpha power values for each subject were extracted and plotted into a graph, as shown in Figure 3. It can be observed that the mean alpha power initially decreases and then increases dramatically until the final time interval for Session 1 (i.e. clear sunny day driving). The results show that the mean alpha power increases slightly with time for Session 2 (i.e. rainy day driving), whereas the mean alpha power begins to decrease after the second time interval for Session 3 (rainy night driving). 


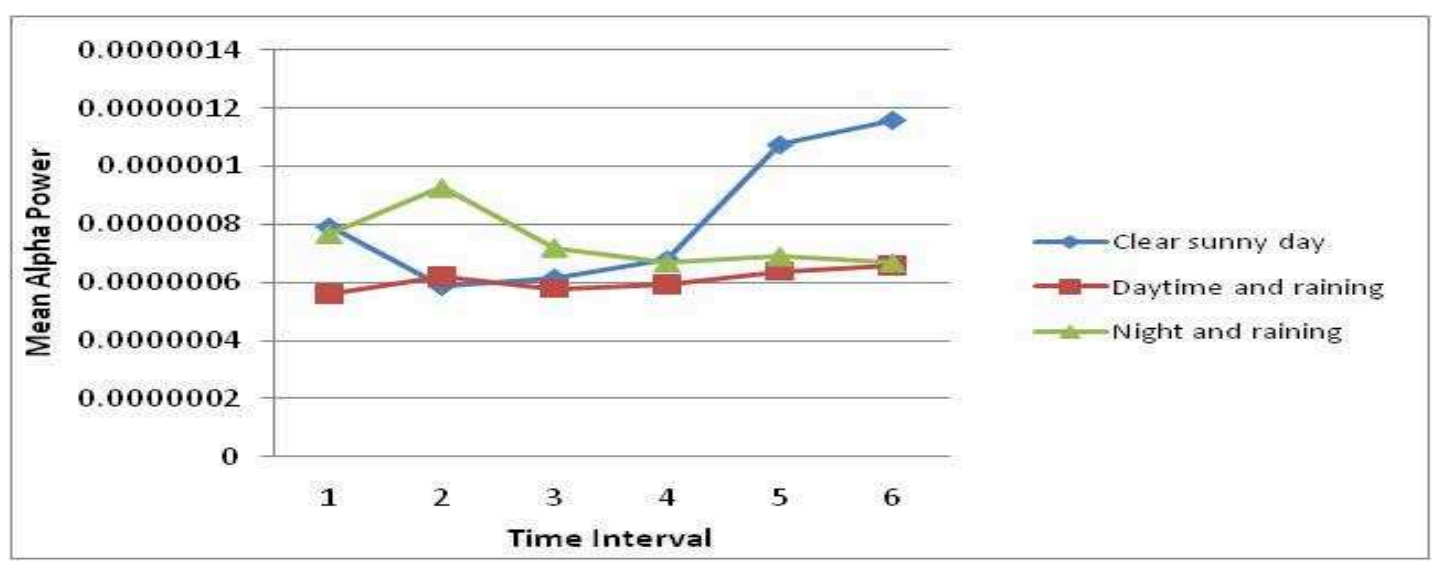

Figure 3: Variations of mean alpha power with respect to time for three driving conditions ( $\mathrm{F}_{\mathrm{Z}}$ and $\mathrm{P}_{\mathrm{Z}}$ locations)

\subsection{Comparison of Mean Alpha Power between Driving Conditions}

The mean alpha power values for the three driving conditions are compared and the statistical results. At $\mathrm{P}<0.05$, it is considered as significant difference. The difference in mean alpha power values at the $\mathrm{F}_{\mathrm{Z}}$ and $\mathrm{P}_{\mathrm{Z}}$ locations is found to be statistically significant for the three driving conditions, whereby, $\chi^{2}(2)=6.333, P=0.042$. It can be seen that there is a significant difference between the driving conditions for the $\mathrm{F}_{Z}$ and $\mathrm{P}_{Z}$ measurement channels. The result reveals that the mental workload is different for each driving condition, particularly for rainy night condition.

\subsection{Discussion}

\subsection{Alpha Activity and its Significance on Mental Workload}

In this study, the mental activity of human operators is investigated via experiment, whereby each participant is required to drive under three environmental conditions (i.e. clear sunny day, rainy day and rainy night). It can be observed that the driving task imposed upon each train driver results in different levels of mental workload during the driving sessions. It is known that a person's level of alertness and attention will be reduced if the person is under-loaded [15], which lead to distractions and diversion of attention, as well as insufficient capacity and time for information processing. Variations of the EGG signals throughout the duration of the experiment are also analyzed, and the experiment clearly demonstrates the effects of driving conditions on the brain signals.

Comparison between driving conditions reveal that there is a significant difference in the mean alpha power for the $\mathrm{F}_{Z}$ and $\mathrm{P}_{\mathrm{Z}}$ channels $(P=0.042)$. This indicates that the alpha activity can be used as a parameter to differentiate the mental workload for each task. The results support the findings of Ryu and Myung [2], which show that the value of alpha can be used to distinguish the difference between levels of difficulty for the tasks. For Session 1, the mean alpha power is found to be low between the initial and middle stages of the experiment, as shown in Figure 3. This may be attributed to the tendency of the train drivers to focus more and engage with the task [16, 17]. The results show that the drivers exhibit a high level of calmness towards the end of the driving session, particularly for clear sunny day condition, as reflected by the drastic increase in alpha activity. It may be possible that the train drivers feel more relaxed towards the end of the session. However, the results contradict with the findings of Myrtek et al. [18] which show that the mental workload increases during the "start" and "braking" modes of driving. 


\subsection{Implications on Occupational Health}

It can be clearly observed from the EEG results that the trend is significantly different for Session 3 (i.e. rainy night driving), compared to Sessions 1 and 2. In Sessions 2 and 3 which involve rainy conditions, it is observed that the mean alpha power decreases between $6-9$ minutes, corresponding to a time interval of 2 and 3. This reveals that the train drivers experience an increase in mental workload after 6 minutes of train driving under rainy conditions, regardless whether it is day or night.

The results also reflect the level of sleepiness amongst the train drivers. It has been shown that night driving induces a higher level of sleepiness $[19,20]$. In this study, the results show a percentage difference in mean alpha power of $37 \%$ between rainy day and rainy night conditions during the early periods of driving. In practice, it is extremely dangerous for train drivers to feel sleepy, or in worse cases, to doze off while working. Therefore, the work schedule or duty roster needs to be specifically and carefully prepared for train drivers such that the drivers can arrange their sleeping hours before reporting for duty. According to Budi et al. [3], there is a distinct relationship between railway accidents and locomotive crew during work shifts. Furthermore, a well-organized work schedule will enhance the motivation of train drivers in carrying out their tasks, which in turn increases productivity and enables them to provide excellent service. McAuliffe et al. [21] highlighted that an effective work schedule is important to increase the motivation and satisfaction of workers.

\subsection{Conclusion}

In this study, the mental workload of train drivers is investigated under three driving conditions, namely, clear sunny day, rainy day and rainy night driving. The mean alpha power indicates a significant difference in the intentional and motivational centres of the train drivers. Furthermore, the mean alpha power also contributes to activity of perception and differentiation, indicating that mental workload load is different for each driving condition. The results reveal that the mean alpha power values are higher during rainy night condition, which indicate that the train drivers experience reduced levels of vigilance. The EEG measurements taken at the $\mathrm{P}_{Z}$ locations (i.e. points that contribute to the primary visual perception of humans) show a decrease in mental workload towards the end of the driving period for rainy night condition, which clearly indicates an increased level of sleepiness. It can be deduced from this study that driving under rainy night conditions results in higher levels of sleepiness and lower levels of alertness, and therefore it is imperative for the management level of the organization to design working environments that will reduce the risk of unfortunate circumstances such as accidents due to inappropriate mental workload of the train drivers. The findings of this study can be utilized to manage work schedules effectively and to improve the working conditions of train drivers. Hence, ergonomics can be practised on a broader perspective, ensuring an excellent balance between the organization as a whole, its people, working practices and technology.

\section{ACKNOWLEDGEMENTS}

The research was supported by Keretapi Tanah Melayu Berhad (KTMB), University Malaya Research Grant (UMRG) and High Impact Research (HIR) University Malaya project UM.C/HIR/MOHE/ ENG/35. 


\section{References}

[1] Hwang, S.-1., Yau, Y.-j., Lin, Y.-t., \& Chen, J. H. (2007). A Mental Workload Predicator Model for the Design of Pre Alarm Systems. Engineering Psychology and Cognitive Ergonomics, 4562, 316-323.

[2] Ryu, K., \& Myung, R. (2005). Evaluation of mental workload with a combined measure based on physiological indices during a dual task of tracking and mental arithmetic. International Journal of Industrial Ergonomics, 35(11), 991-1009.

[3] Budi J. T., Lal, S., \& Fischer, P. (2011). Comparing combinations of EEG activity in train drivers during monotonous driving. Expert Systems with Applications, 38(1), 996-1003.

[4] Rail Safety and Standards Board. (2005). Train Driver Workload Principles Guidance Note Train Driver Mental Workload. London: The Institute For Occupational Ergonomics Centre For Rail Human Factors.

[5] Parkes, A. M. (1991). Data Capture Techniques For RTI Usability Evaluation. Paper presented at the DRIVE Conference (1991 : Brussels, Belgium). Advanced telematics in road transport. Vol. II, Brussels, Belgium.

[6] Mayser C, Piechulla W, Weiss K.-E, \& König W. (2003, May 07th-09th). Driver workload monitoring. Paper presented at the The 50th-Anniversary Conference of the GfA and the XVII Annual ISOES Conference, Munich.

[7] Verwey, W. B. (2000). On-line driver workload estimation. Effects of road situation and age on secondary task measures. Ergonomics, 43, 187-209.

[8] De Waard, D. (1996). The measurement of drivers' mental workload. Ph.D, University of Groningen, Haren, The Netherlands.

[9] Lei, S., \& Roetting, M. (2011). Influence of Task Combination on EEG Spectrum Modulation for Driver Workload Estimation. Human Factors: The Journal of the Human Factors and Ergonomics Society, 53(2), 168-179.

[10] Rabbi, A. F., Ivanca, K., Putnam, A. V., Musa, A., Thaden, C. B., \& Fazel-Rezai, R. (2009, 3-6 Sept. 2009). Human performance evaluation based on EEG signal analysis: A prospective review. Paper presented at the Engineering in Medicine and Biology Society, 2009. EMBC 2009. Annual International Conference of the IEEE.

[11] Chen, D., \& Vertegaal, R. (2004). Using Mental Load for Managing Interruptions in Physiologically Attentive User Interfaces CHI. Vienna, Austria.

[12] Gillberg, M., Kecklund, G., \& Åkerstedt, T. (1996). Sleepiness and performance of professional drivers in a truck simulator - Comparisons between day and night driving. Journal of Sleep Research, 5(1), 12-15.

[13] Hallvig, D., Anund, A., Fors, C., Kecklund, G., Karlsson, J. G., Wahde, M., \& Åkerstedt, T. (2013). Sleepy driving on the real road and in the simulator-A comparison. Accident Analysis \& Prevention, 50(0), 44-50.

[14] Andreassi, J. L. (2000). Psychophysiology: Human Behavior and Physiological Response. New Jersey London: Lawrence Erlbaum Associates, Hillsdale.

[15] De Waard, D., \& Brookhuis, K. A. (1997). On the measurement of driver mental workload. Traffic and Transport Psychology: Theory and Application, 161-171.

[16]K. Seen , S. Mohd Tamrin, \& G. Meng. (2010). Driving Fatigue and Performance among Occupational Drivers in Simulated Prolonged Driving. Global Journal of Health Science, 2(1).

[17] Nikhil R. Pal, Chien-Yao Chuang, Li-Wei Ko, Chih-Feng Chao, Tzyy-Ping Jung, Sheng-Fu Liang, \& Lin, C.-T. (2008). EEG-Based Subject- and Session-independent Drowsiness Detection: An Unsupervised Approach. EURASIP Journal on Advances in Signal Processing. 
[18] Myrtek, M., Deutschmann-Janicke, E., Strohmaier, H., Zimmermann, W., Lawerenz, S., BrÜGner, G., \& MÜLler, W. (1994). Physical, mental, emotional, and subjective workload components in train drivers. Ergonomics, 37(7), 1195-1203.

[19]Lowden, A., Anund, A., Kecklund, G., Peters, B., \& Åkerstedt, T. (2009). Wakefulness in young and elderly subjects driving at night in a car simulator. Accident Analysis \& Prevention, 41(5), 1001-1007.

[20] Otmani, S., Rogé, J., \& Muzet, A. (2005). Sleepiness in professional drivers: Effect of age and time of day. Accident Analysis and Prevention, 37(5), 930-937.

[21] McAuliffe, E., Manafa, O., Maseko, F., Bowie, C., \& White, E. (2009). Understanding job satisfaction amongst mid-level cadres in Malawi: the contribution of organisational justice. Reproductive Health Matters, 17(33), 80-90. 